\title{
Nail Sarcoidosis Presenting with Longitudinal Erythronychia
}

\author{
Paula P.M. van Lümig Marcel C. Pasch \\ Department of Dermatology, Radboud University Medical Center, Nijmegen, The Netherlands
}

\section{Established Facts}

- Nail changes in sarcoidosis are nonspecific and diverse.

- Nail involvement and bone involvement are both regarded as features of chronic and systemic sarcoidosis.

\section{Novel Insights}

- Longitudinal erythronychia is a new clinical presentation of nail sarcoidosis and should be recognized as such, as (paucisymptomatic) bone involvement of the underlying distal phalanges and systemic involvement are present in most patients with sarcoidosis of the nails and should be screened for.

\section{Keywords}

Nail · Sarcoidosis · Longitudinal erythronychia

\section{Abstract}

A 37-year-old woman presented with progressive longitudinal erythronychia and onychorrhexis of the toenails. She had a history of sarcoidosis of the lung and nose, which was silent without treatment at the time of presentation. Histopathological examination of a nail matrix biopsy revealed granulomas with palisading histiocytes in the connective tissue and a lymphocytic infiltrate in and around the granulomas without necrosis. Based on the clinical presentation, medical history, and histopathological examination, the diagnosis of nail sarcoidosis was made. Treatment with triamcinolone acetonide $40 \mathrm{mg} / \mathrm{mL}$ resulted in the disappearance of the onychorrhexis and a significant improvement of erythronychia. To our knowledge, a clinical presentation with longitudinal erythronychia as seen in our patient has not been previously described. Bone involvement of the underlying distal phalanges and systemic involvement can be paucisymptomatic but are

\section{KARGER}

(c) 2017 S. Karger AG, Basel

E-Mail karger@karger.com

www.karger.com/sad present in most patients with sarcoidosis of the nails. Nail and bone involvement are both regarded as features of chronic and systemic sarcoidosis. Screening for bone and systemic involvement should be performed in all patients with nail sarcoidosis, as this may influence decisions on treatment and follow-up. Therefore, it is important to recognize longitudinal erythronychia as a possible clinical sign of nail sarcoidosis.

(c) 2017 S. Karger AG, Basel

\section{Introduction}

Sarcoidosis is a multi-organ systemic disease of unknown cause, characterized histopathologically by noncaseating epithelioid cell granulomas, usually without surrounding lymphocytic infiltration (so-called "naked" granulomas) [1]. Nail involvement in sarcoidosis is rare, with prevalence figures available ranging from $0.3 \%$ [2] to $1.6 \%[3]$.

Nail changes described in sarcoidosis are nonspecific and diverse, including nail plate hyperkeratosis/nail 


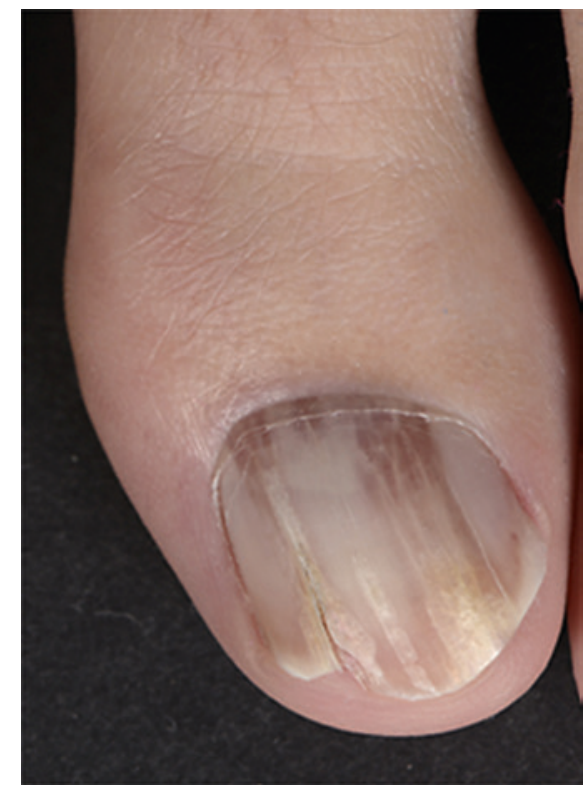

Fig. 1. Nail of the left great toe before treatment.

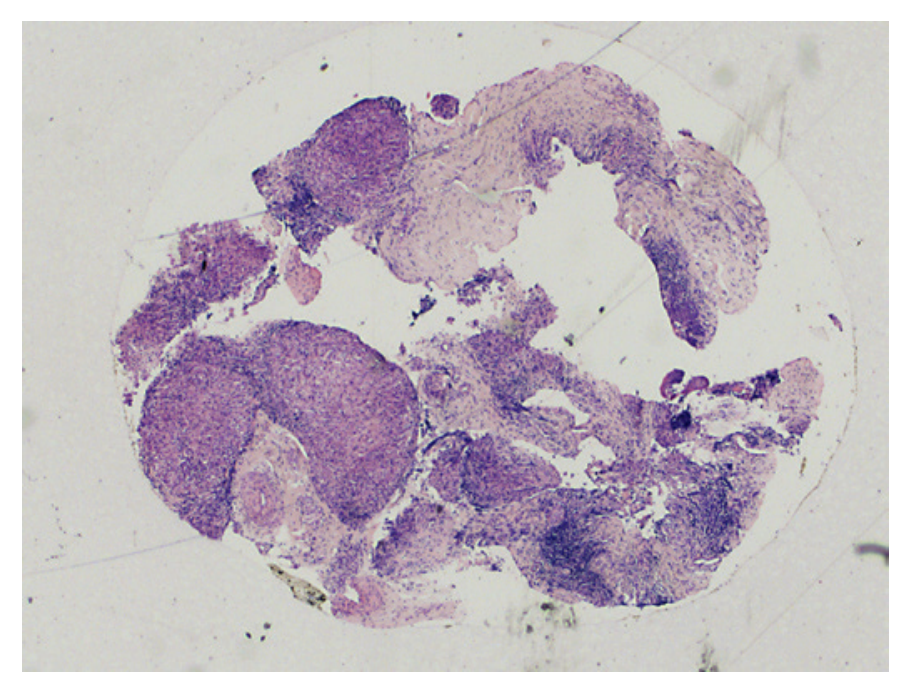

Fig. 2. Histopathological examination of nail matrix biopsy (HE, $\times 25$ ) showing some lymphocytes in the epithelium, granulomas with palisading histiocytes in the connective tissue, and a lymphocytic infiltrate in and around the granulomas without necrosis.

On physical examination, polydactylous longitudinal erythronychia with subungual erythematous macules and onychorrhexis of multiple toenails were observed (Fig. 1). There were no periungual or skin changes. The differential diagnosis consisted of sarcoidosis and known conditions associated with polydactylous longitudinal erythronychia of the nails, e.g., lichen planus, Darier disease, amyloidosis, acantholytic dyskeratotic epidermal nevus, acrokeratosis verruciformis of Hopf, celiac disease, and pseudobulbar syndrome [7]. Several of these conditions could already be excluded from the clinical presentation.

Histopathological examination of a nail matrix biopsy revealed some lymphocytes in the epithelium, rather large granulomas with palisading histiocytes in the connective tissue, and a lymphocytic infiltrate in and around the granulomas without necrosis (Fig. 2, 3). Auramine staining showed no acid-fast bacilli. Periodic acidSchiff and Brown-Hopps staining showed no fungi or bacteria, respectively. ACE level was normal (66 U/L). On radiography of the chest and distal phalanges, no signs of active sarcoidosis were detected. Based on the clinical presentation, medical history, and histopathological examination, the diagnosis of nail sarcoidosis was made. The absence of bone changes was favorable, as both nail involvement and bone involvement are considered as signs of chronic and systemic sarcoidosis.

Initially, the patient was treated with triamcinolone acetonide $10 \mathrm{mg} / \mathrm{mL}$ injections ( $0.05 \mathrm{~mL}$ per proximal nail fold) in the nail matrix area of 3 nails without response. Treatment with triamcinolone acetonide $40 \mathrm{mg} / \mathrm{mL}$ injections $(0.05 \mathrm{~mL}$ per nail matrix area) was partially successful, resulting in the disappearance of the onychorrhexis and a significant improvement of erythronychia (Fig. 4). The patient was satisfied by the result, so no further treatment was given. 


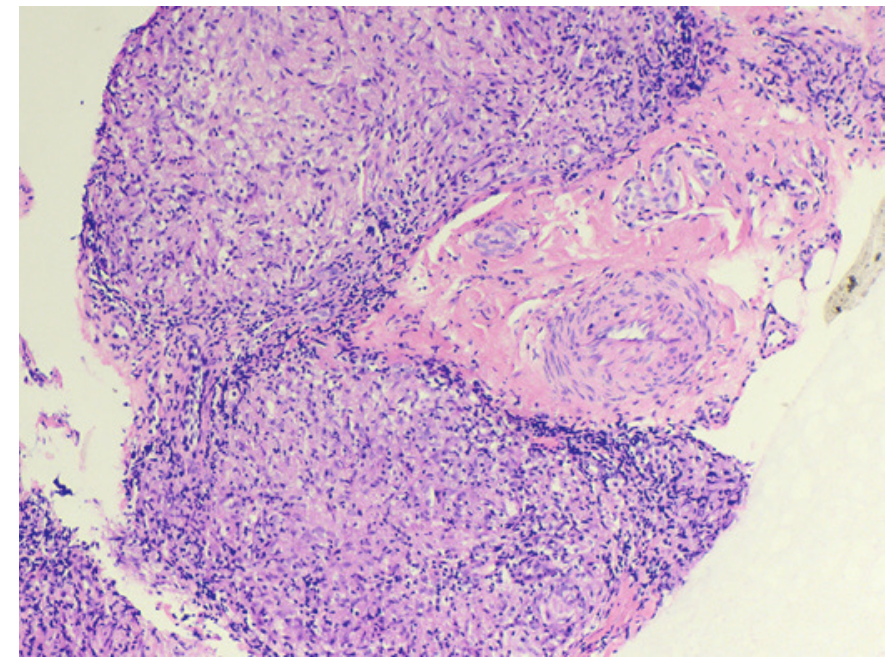

Fig. 3. Histopathological examination of nail matrix biopsy (HE, $\times 100$ ) showing some lymphocytes in the epithelium, granulomas with palisading histiocytes in the connective tissue, and a lymphocytic infiltrate in and around the granulomas without necrosis.

\section{Discussion}

To our knowledge, nail sarcoidosis presenting with longitudinal erythronychia as seen in our patient has not been previously described. Sarcoidosis of the nails is almost always associated with bone changes in the underlying distal phalanges on radiographic examination, most often consisting of bony resorption with a lacy trabecular pattern or bone cysts [8]. Bone changes are asymptomatic in about $50 \%$ of patients [9].

Nail changes and classical bone changes in a patient with a medical history of sarcoidosis may make a nail biopsy unnecessary. However, nail changes in sarcoidosis are nonspecific, and nail sarcoidosis in the absence of bone involvement has occasionally been reported, as was the case in our patient $[6,10,11]$. In addition, longitudinal erythronychia as a clinical sign of nail sarcoidosis as seen in our patient has not been described previously. Therefore, the nail biopsy was essential in this patient and led to the diagnosis of nail sarcoidosis with a unique presentation.

Nail involvement and bone involvement are both regarded as features of chronic and systemic sarcoidosis [12]. Momen and Al-Niaimi [5] reviewed the literature on nail sarcoidosis and reported on systemic involvement in their 33 identified cases of nail sarcoidosis. Histopath-

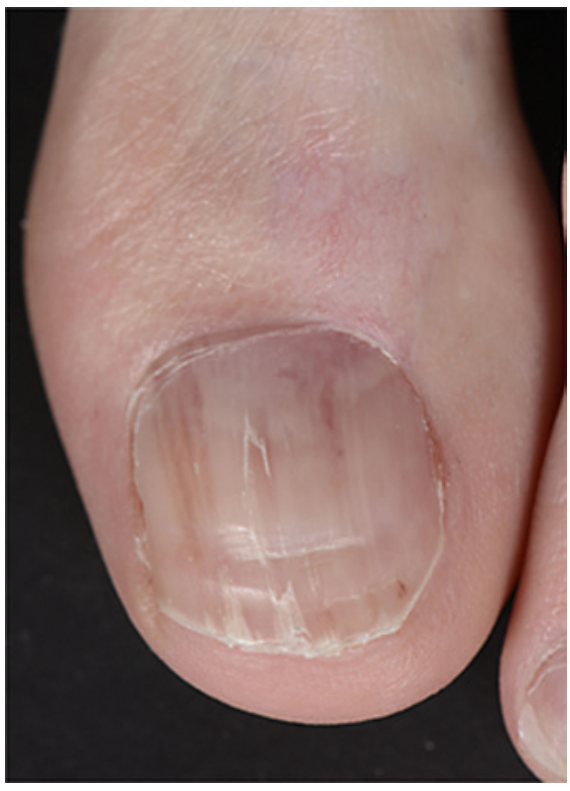

Fig. 4. Nail of the left great toe after treatment with triamcinolone acetonide $10 \mathrm{mg} /$ $\mathrm{mL}$ (first) and triamcinolone acetonide 40 $\mathrm{mg} / \mathrm{mL}$ (later). ological confirmation from nail biopsies was obtained in only 7 (21\%) of these patients. In their review, lupus pernio, dactylitis, lymphadenopathy, and pulmonary fibrosis were present in $36,27,33$, and $18 \%$ of patients, respectively.

As bone involvement and systemic involvement can be paucisymptomatic but may influence decisions on treatment and follow-up, radiographic examination of the hands or feet and screening for systemic involvement by at least a chest radiograph is advised in patients with nail sarcoidosis [5], as was done in this case. Therefore, it is important to recognize longitudinal erythronychia as a possible clinical sign of nail sarcoidosis.

\section{Statement of Ethics}

The patient's informed consent for publication of this case report was obtained. Publication was also approved by the authors' institution.

\section{Disclosure Statement}

P.P.M. van Lümig and M.C. Pasch have no conflicts of interest to declare. There was no funding for this work. 


\section{References}

1 Bolognia JL, Jorizzo JL, Schaffer JV: Dermatology, ed 3. Elsevier, 2012.

2 Patel KB, Sharma OP: Nails in sarcoidosis: response to treatment. Arch Dermatol 1983; 119:277-278.

3 Veien NK, Stahl D, Brodthagen H: Cutaneous sarcoidosis in Caucasians. J Am Acad Dermatol 1987; 16:534-540.

4 Cox NH, Gawkrodger DJ: Nail dystrophy in chronic sarcoidosis. Br J Dermatol 1988;118: 697-701.

5 Momen SE, Al-Niaimi F: Sarcoid and the nail: review of the literature. Clin Exp Dermatol 2013;38:119-124; quiz 125.
6 Wakelin SH, James MP: Sarcoidosis: nail dystrophy without underlying bone changes. $\mathrm{Cu}$ tis $1995 ; 55: 344-346$.

7 Cohen PR: Longitudinal erythronychia: individual or multiple linear red bands of the nail plate: a review of clinical features an associated conditions. Am J Clin Dermatol 2011;12: 217-231.

8 Albers BK, Sluzevich JC, Garner HW: Sarcoidosis: radiographic manifestations in the nails and distal phalanges. Skeletal Radiol 2016;45:717-721.
9 Neville E, Carstairs LS, James DG: Sarcoidosis of bone. Q J Med 1977;46:215-227.

10 Kawaguchi M, Suzuki T: Nail dystrophy without bony involvement in a patient with chronic sarcoidosis. J Dermatol 2014;41:194-195.

11 Noriega L, Criado P, Gabbi T, Avancini J, Di Chiacchio N: Nail sarcoidosis with and without systemic involvement: report of two cases. Skin Appendage Disord 2015;1:87-90.

12 Santoro F, Sloan SB: Nail dystrophy and bony involvement in chronic sarcoidosis. J Am Acad Dermatol 2009;60:1050-1052. 